\title{
A Ten Year Review of the Biochemical Profile of Patients Diagnosed with Multiple Myeloma in Port Harcourt, Nigeria
}

\author{
Ntuen $\mathrm{N}^{1}$, Korubo K.I. ${ }^{2}$ \\ ${ }^{1}$ Department Of Chemical Pathology, University Of Port Harcourt Teaching Hospital \\ ${ }^{2}$ Department Of Haematology \& Blood Transfusion, University Of Port Harcourt Teaching Hospital
}

\begin{abstract}
Background: Multiple Myeloma is the commonest haematological malignancy in people of African descent. Diagnosis depends on the presence of plasma cells which produce monoclonal proteins or abnormal free light chains.

Aims \& Methods: The aim was to assess certain biochemical parameters in patients diagnosed with multiple myeloma. This was a ten year retrospective hospital based study.

Results: There was a total of 29 patients with a male to female ratio of 1.9:1. Median age at diagnosis was 60 years. There were $75.9 \%$ with anaemia and $51.7 \%$ had renal impairment (chronic kidney stages $2-4$ ). Only $6.7 \%$ had hypercalcaemia, while hypocalcaemia was more common (20\%). Four cases did not show a monoclonal protein on serum protein electrophoresis while 3 (11.1\%) had a biclonalgammopathy. All cases with monoclonal proteins had an $M$-spike located in the gamma region. Of those that had free light chains assay done, $76.9 \%$ had kappa chain involvement while in $23.1 \%$ cases the lambda chains were involved.

Conclusion: Our study revealed a lower median age of 60 years. There were uncharacteristically more cases with hypocalcaemia than expected hypercalcaemia. More than half had anaemia with renal impairment.
\end{abstract}

Keywords: Multiple myeloma, MM, Biochemical parameters, Nigeria

\section{Introduction}

Multiple Myeloma (MM) is a neoplasm of the bone marrow that involves clonal proliferation of malignant plasma cells which produce monoclonal proteins (M-proteins or paraproteins)detected in the blood and urine, as well as a complex array of clinical manifestations including hypercalcaemia, renal impairment, anaemia, lytic bone lesions (CRAB), and hypogammaglobulinaemia.

Multiple myeloma accounts for $1 \%$ of human cancers, $2 \%$ of cancer deaths, $10-15 \%$ of hematological malignancies and $20 \%$ of deaths related to haematological malignancies.' The median age at diagnosis is 70 years and the incidence increases with age. MMisthe most common haematological malignancy in people of African descent and is twice as common in blacks than other races. The exact cause of MM is unknown, however there is a potential genetic susceptibility and there are several reports of MM occurring in families. Patients with MM evolve from preclinical stages of monoclonal gammopathy of undetermined significance (MGUS), or smoldering multiple myeloma (SMM) which do not require therapy. Development of end organ damage or clinical symptoms heralds the onset of MM. The diagnosis of this disorder depends on the presence of characteristic clinical findings (includinganaemia,bone pains andfeatures of renal insufficiency) with identification of abnormal monoclonal plasma cells in the bone marrow, M-proteins in the urine or serum, evidence of end organ damage, lytic bone lesions, hypercalcaemia and immunodeficiency. A number of factors such as renal function, haemoglobin concentration, serum calcium, extent of bone lesion, serum albumin, lactate dehydrogenase, beta 2 microglobulin and performance status at the time of diagnosis are known to be important in relation to survival in patients with MM.

\section{Aim And Methods}

The aim of this study was to assesscertain biochemical parameters at first presentation in patients newly diagnosed with MM, with specific reference to renal and hepatic function, paraprotein concentration and presence of light chian disease.

This was a hospital-based retrospective study conducted at the University of Port Harcourt Teaching Hospital which is a tertiary institution in the South-South regionof Nigeria. Data was obtained from the case notes retreived from both the department of haematology and blood transfusion, as well as the medical records department. All confirmed cases of MM between August 2006 and July 2016 were included in the study. Diagnosis of MM was made using bone marrow aspiration, presence of monoclonal protein on serum protein electrophoresis and/ or serum free light chains analysis.

Biodata extracted included age, sex and ethnicity. Other data included laboratory investigations done at first presentation: full blood count (FBC), erythrocyte sedimentation rate (ESR), bone marrow aspiration 
(BMA), serum electrolytes, urea and creatinine (EUCR), liver functions test (LFT), fasting plasma glucose (FPG), serum protein electrophoresis (SPE) and serum free light chains (FLC).Data was analyzed using statistical software package Microsoft Xcel® 2013.

\section{Results}

A total of 29 patients were diagnosed with MMbetween August 2006 and July 2016. All patients were Nigerians. Males were twice as affected as females (19 males and 10 females with a M:F ratio of 1.9:1). The mean age at presentation was $54.2 \pm 15.9$ years, with a median age of 60 (range $24-83$ years), see Figure 1.The average weight was $75.9 \pm 15.6 \mathrm{~kg}$. There were $25(86.2 \%)$ caseswith anaemia; mean haemoglobin $(\mathrm{Hb})$ concentration was $8.4 \pm 1.8 \mathrm{~g} / \mathrm{dL}$. Table 1 shows the full blood count (FBC) parameters and erythrocyte sedimentation rate of the subjects.

The values of the biochemical parameters are presented in Table 2. Although the serum creatinine value was elevated in $9(31 \%)$ patients; $15(51.7 \%)$ had renal impairment with estimated glomerular filtration rate (eGFR) values $<90$ fitting intochronic kidney disease stages 2-4 (Fig. 2). The creatinine was significantly higher in patients with renal impairment compared to those without $(162 \mathrm{mmol} / \mathrm{L}$ vs. $69.4 \mathrm{mmol} / \mathrm{L}$; $\mathrm{p}$-value 0.004); while the eGFR was significantly lower in those with renal impairment compared to those without (56 vs. 146.2; p-value 0.0001). Although the Hb concentration was lower in those with renal impairment, this was not statistically significant $(\mathrm{Hb} 7.7 \mathrm{~g} / \mathrm{dL}$ vs. $9 \mathrm{~g} / \mathrm{dL}$; $\mathrm{p}$-value 0.06$)$. There was a weak positive correlation between the eGFR and $\mathrm{Hb}$ concentration $(+0.22)$; while a weak negative correlation existed between creatinine and $\mathrm{Hb}$ concentration (-0.23). A majority of the cases presented with acidosis (15, 60\%), renal impairment $(15,57.7 \%)$, hyperuricaemia $(12,57.1 \%)$, hypoalbuminaemia $(12,66.7 \%)$ and hyperproteinaemia $(9,50 \%)$. Using the corrected calcium, only one patient $(6.7 \%)$ had hypercalcaemia while $3(20 \%)$ had hypocalcaemia.

For the diagnosis of myeloma, all patients $(100 \%)$ had a bone marrow aspiration (mean plasmacytosis was $39.7 \pm 24.2 \%), 18(62.1 \%)$ had SPE while $13(44.8 \%)$ had serum FLC done. Urinary Bence Jones proteins (BJP) was assayed in $11(37.9 \%)$ patients and was positive in all cases. Of the 18 (62.1\%) patients who had serum protein electrophoresis done, $4(22.2 \%)$ had non-secretory myeloma (no monoclonal protein detected), while $14(77.8 \%)$ had monoclonal protein detected in serum with a mean of $39.1 \pm 37.1 \mathrm{~g} / \mathrm{L}$. Three patients $(11.1 \%)$ had 2 monoclonal peaks present. All cases (100\%) including those with 2 monoclonal peaks had the Mproteins located in the gamma region on SPE, except 1 (5.6\%) case who had two monoclonal peaks of which one peak was located in the beta region $(58 \mathrm{~g} / \mathrm{L})$ while the other peak was in the gamma region $(4 \mathrm{~g} / \mathrm{L})$.

Of the 29 patients, $13(44.8 \%)$ had serum free light chains done. Patients with kappa chain involvement were significantly more $(10,76.9 \%)$ than those with lambda chain involvement $(3,23.1 \%)$. Amongst the cases with increased kappa chains, 6 (60\%) had diagnostic values >100mg/L (range $310-5850 \mathrm{mg} / \mathrm{L})$; while 4 (40\%) had elevated kappa values but $<100 \mathrm{mg} / \mathrm{L}$ (range $28.8-73.5 \mathrm{mg} / \mathrm{L}$ ). The four cases of non-secretory myeloma who did not have an M-protein on SPE all had light chain disease involving the kappa chains(mean $1969.6 \mathrm{mg} / \mathrm{L}$; range $73.5-5,850 \mathrm{mg} / \mathrm{L})$.

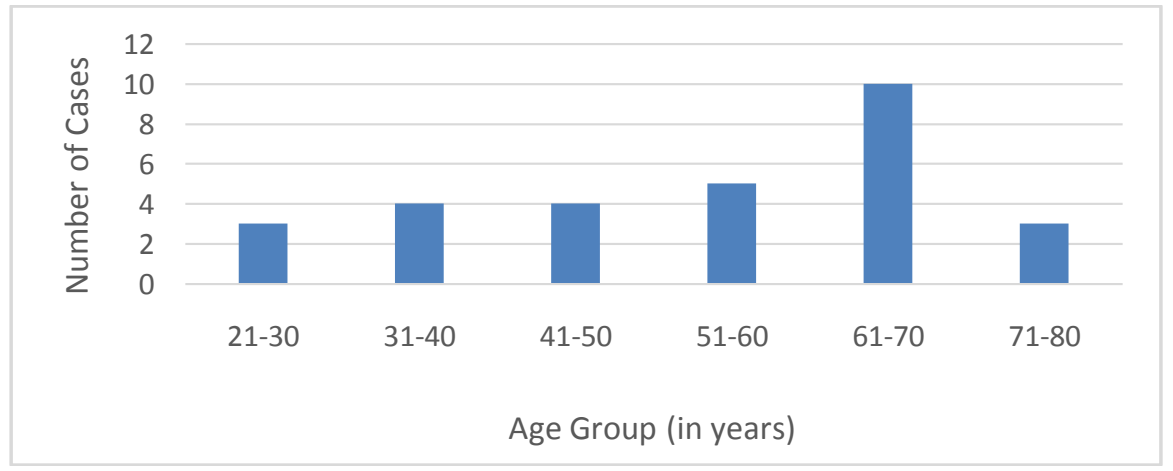

Figure 1: Distribution of age groups among cases

Table 1:

\begin{tabular}{|l|c|c|c|c|}
\hline \multicolumn{1}{|c|}{ Haematological Parameter } & Mean $( \pm \mathrm{Sd})$ & Range & $\begin{array}{c}\text { No. (\%) With } \\
\text { Values Lower } \\
\text { Than Reference } \\
\text { Range }\end{array}$ & $\begin{array}{c}\text { No. (\%) With } \\
\text { Values Higher } \\
\text { Than Reference } \\
\text { Range }\end{array}$ \\
\hline Hb. Conc (G/Dl) & $8.4( \pm 1.8)$ & $5.1-$ & $22(75.9)$ & $0(0)$ \\
& $25.7( \pm 5.7)$ & $16-35$ & $21(72.4)$ & $0(0)$ \\
\hline Pcv $(\%)$ & $5.8( \pm 3)$ & $1.7-$ & $3(10.3)$ & $2(6.9)$ \\
& & 13.5 & & \\
\hline
\end{tabular}


A ten year review of the biochemical profile Of patients diagnosed with multiple myeloma...

\begin{tabular}{|l|r|c|c|c|}
\hline Platelets $\left(\mathrm{X} 10^{9} / \mathrm{L}\right)$ & $207( \pm 148.6)$ & $18-582$ & $8(27.5)$ & $3(10.3)$ \\
\hline Esr & $107.5( \pm 45)$ & $24-150$ & $0(0)$ & $23(79.3)$ \\
\hline Bm Plasmacytosis & $36.9( \pm 24.2)$ & $5-85$ & $0(0)$ & $29(100)$ \\
\hline
\end{tabular}

Table 2

\begin{tabular}{|c|c|c|c|c|c|}
\hline Biochemical Parameter & Mean & $( \pm \mathrm{Sd})$ & Range & $\begin{array}{c}\text { No. (\%) With } \\
\text { Values Lower } \\
\text { Than Reference } \\
\text { Range }\end{array}$ & $\begin{array}{c}\text { No. (\%) With } \\
\text { Values Higher } \\
\text { Than Reference } \\
\text { Range }\end{array}$ \\
\hline Sodium & 137.4 & $( \pm 6.4)$ & $122-146$ & $2(8)$ & $5(20)$ \\
\hline Potassium & 4.0 & $( \pm 0.8)$ & $2.8-6.7$ & $5(20)$ & $4(16)$ \\
\hline Bicarbonate & 24.9 & $( \pm 14.7)$ & $13-92$ & $15(60)$ & $1(4)$ \\
\hline Urea & 4.6 & $( \pm 2.6)$ & $1.3-10$ & $8(30.8)$ & $9(34.6)$ \\
\hline Creatinine (60-120) & 122.8 & $( \pm 92.4)$ & $43-500$ & $2(7.7)$ & $9(34.6)$ \\
\hline Egfr (Ml/Min/1.73m2) & 94.2 & $( \pm 58.2)$ & $15-222$ & $15(57.7)$ & $11(42.3)$ \\
\hline Fbg & 5.2 & $( \pm 2.1)$ & $0.15-9.6$ & $1(3.4)$ & $10(34.5)$ \\
\hline Uric Acid & 476.7 & $( \pm 237.6)$ & $151-1,100$ & $0(0)$ & $12(57.1)$ \\
\hline $\mathrm{Ca} 2+$ & 2.1 & $( \pm 0.3)$ & $1.5-2.6$ & $5(33.3)$ & $0(0)$ \\
\hline Corr. Ca2+ & 2.3 & $( \pm 0.3)$ & $1.79-2.8$ & $3(20)$ & $1(6.7)$ \\
\hline Total Bilirubin & 9.7 & $( \pm 3.9)$ & $5-19$ & $0(0)$ & $1(7.8)$ \\
\hline Conj.Bilirubin & 1.4 & $( \pm 0.8)$ & $0-2$ & $1(14.2)$ & $0(0)$ \\
\hline Alt & 24.1 & $( \pm 12.5)$ & $2-48$ & $2(14.3)$ & $2(14.3)$ \\
\hline Ast & 31.7 & $( \pm 17.7)$ & $3-60$ & $1(3.4)$ & $5(17.2)$ \\
\hline Alk Phos & 171.9 & $( \pm 193.3)$ & $5.3-620$ & $3(25)$ & $4(33.3)$ \\
\hline Kappa & 791 & $\begin{array}{l}( \pm 1,593 \\
6)\end{array}$ & $\begin{array}{c}0.87- \\
5,850\end{array}$ & $1(7.7)$ & $10(77)$ \\
\hline Lambda & 1,278 & $\begin{array}{l}( \pm 3,467 . \\
4)\end{array}$ & $\begin{array}{c}6.9- \\
12,352\end{array}$ & $0(0)$ & $4(30.8)$ \\
\hline Total Protein & 93 & $( \pm 35.3)$ & $53-160$ & $1(5.6)$ & $9(50)$ \\
\hline Albumin & 31.9 & $( \pm 9.6)$ & $18-48$ & $12(66.7)$ & $0(0)$ \\
\hline Alpha-1-Glob & 3.5 & $( \pm 1.2)$ & $2-6.6$ & $1(5.6)$ & $6(33.3)$ \\
\hline Alpha_2-Glob & 8.1 & $( \pm 2.7)$ & $2.8-13.8$ & $2(11.1)$ & $5(27.8)$ \\
\hline Beta-Glob- & 15.4 & $( \pm 21.1)$ & $3.7-75.1$ & $5(27.8)$ & $4(22.2)$ \\
\hline Gamma Glob & 31.5 & $( \pm 36.9)$ & $2.3-109.6$ & $5(27.8)$ & $10(55.6)$ \\
\hline Paraprotein & 37.9 & $( \pm 36.8)$ & $0-107.5$ & 4 (16.7) & $15(83.3)$ \\
\hline
\end{tabular}

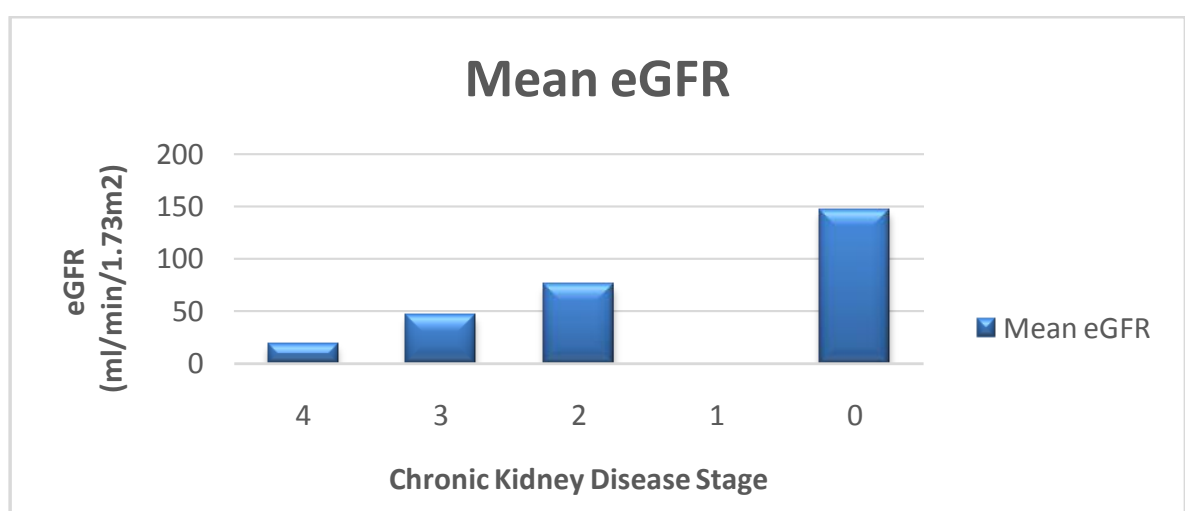

Figure 2: Mean estimated Glomerular Filtration Rate (eGFR) and chronic kidney disease stage of patients with renal failure

\section{Discussion}

A total of 29 cases were studied within the ten year period.The mean age of incidence was $54.2 \pm 15.9$ years with a lower median age of $60 \pm 15.9$ years compared to other studies with median age of 66-73 years. ${ }^{1}$, ${ }^{6}$ However, MM has been found to occur at a lower age in blacks than other races $\left({ }^{(6)}\right.$ as seen in our study where up to $14(48.3 \%)$ cases were under the age of 60 years and $7(24.1 \%)$ were under 40 years of age. As expected in $\mathrm{MM}^{(6)}$, there was a male preponderance.

The serum sodium and potassium analysis was insignificant. Majority of the patients[60\%] presented with metabolic acidosis with a low mean bicarbonate level. Our study showed $57.1 \%$ cases with hyperuricaemia.The mean total uncorrected calcium was $2.1 \pm 0.3 \mathrm{mmol} / \mathrm{L}$ giving a $33 \%$ hypocalcaemia whereas no patient had hypercalcaemia. However, on correcting the calcium value with the serum albumin concentration, the meancorrected (adjusted) calcium value was $2.3 \pm 0.3 \mathrm{mmol} / \mathrm{L}$. This highlights the importance of using 
corrected or adjusted calcium in interpretation of calcium assays. Withthe adjusted calcium, there was hypercalcaemiain only $6.7 \%$ of cases. This is unexpected as in MM there is typically hypercalcaemia in up to $45 \%$ of cases. This also constitutes part of the diagnostic criteria of CRAB, where C denotes hypercalcaemia. ${ }^{6}$ Despite using the adjusted calcium, up to $20 \%$ still had hypocalcaemia which is not characteristic of MM at diagnosis. Hypocalcaemia may occur in $\mathrm{MM}$ as a side effect following the use of bisphosphonates or monoclonal antibodies against receptor activator of nuclear factor kB ligand (RANKL) such as Denosumab as therapy for hypercalcaemia.

Production of paraproteins by the malignant plasma cells in MM causes hyperproteinaemia associated with hypoalbuminaemia and this was the case in our study with a high mean total protein of $93( \pm 35) \mathrm{g} / \mathrm{dL}$ and low albumin levels of $31.9( \pm 9.5) \mathrm{g} / \mathrm{dL}$ respectively. Total protein to albumin ratio was increased in all the patients.Detection of an M-spike on SPE is one of the hallmarks in diagnosis of MM. Out of the 18 cases of multiple myeloma that had SPE done, 14(77.8\%) were found to have monoclonal gammopathy as expected in MM.Although non-secretory myeloma (where there is an absence of monoclonal proteins) occurs in $<5 \%$ cases of MM, this number was much higher in our study where 4 of the 18 cases $(22.2 \%)$ with SPE did not reveal a monoclonal protein. However this number may be due to the small sample size of this study and the fact that of the 29 cases, SPE was done in only 18 of them as the facility to perform SPE was available only recently in our institution.

The presence of monoclonal proteins in the serum or urine causes a spike or peak in the SPE pattern.This spike is usually located in the gamma region, less frequently in the beta region and rarely in the alpha regions, as seen in our cases.Of the 14 cases with monoclonal proteins, all $(100 \%)$ had the spike or Mprotein located in the gamma region on SPE, but one case $(5.6 \%$ ) had a spike in the beta region (although this case actuallyhad a biclonalgammopathy where there were $2 \mathrm{M}$-spikes on SPE,one peak was in the beta region and the other in the gamma region). Our findings are similar to that by Dash et al whoreported that the M-spike was localized in the gamma region in $89 \%$ cases, beta region in $8 \%$ cases and alpha region in $1 \%$ cases. In about $2-9 \%$ of cases, monoclonal proteins may be located in more than one region on SPE (biclonalgammopathy), this was present in $11.1 \%$ of our cases. Chopra et al reported $84.8 \%$ of myeloma cases had an M-spike in the gamma region with $15.2 \%$ in the beta globin region while Tripathyet al reported M-spike of the gamma region in $87.5 \%$ cases and $12.5 \%$ in the beta region. ${ }^{16}$, Of the 13 patients who had free light chains assay done, majority had kappa chain involvement (76.9\%)than lambda chain involvement which was seen in $23.1 \%$ cases. In 2015, the international myeloma working group updated the diagnostic criteria for MM to include serum involved/uninvolved free light chain ratio $\geq 100$, provided the involved FLC is $\geq 100 \mathrm{mg} / \mathrm{L}$. Among the cases with increased kappa chains, $60 \%$ had diagnostic values (involved chain $>100 \mathrm{mg} / \mathrm{L}$; involved/ uninvolved ratio $>100$ )while in $40 \%$, although there was elevated kappa values, these wereless than the diagnostic criteria (involved kappa chains were $<100 \mathrm{mg} / \mathrm{l}$; range 28.37 - $73 . \mathrm{gmg} / \mathrm{L}$ ).

$\mathrm{MM}$ is a cause of renal impairment. Although the creatinine value was elevated in $31 \%$ patients, $51.7 \%$ had renal impairment with the estimated glomerular filtration rate (eGFR)values $<90 \mathrm{ml} / \mathrm{min} / 1.73 \mathrm{~m}^{2}$ which spans along stages 2-4 of chronic kidney disease.Renal dysfunction in MM is one of the complications that requires careful attention as it is one of the factors that predicts survival.Renal impairment may occur via various mechanisms. These include the deposition of free light chains in the glomeruli, hypercalcaemia, dehydration, the use of contrast media, nephrotoxic medication and recurrent urinary tract infections. Free light chains are mainly deposited in glomeruli with massive fibrillary structure associated with insidious progression of renal failure.Light chain myeloma accounts for $40-60 \%$ of severe myeloma associated kidney injury reflecting the nephrotoxicity of the filtered light chains. Although more than half $(51.7 \%)$ of our cases had renal impairment, this study did not investigate the causes of renal impairment in these patients. However, of the 15 cases with renal impairment, 6 had FLC done of which $4(66.7 \%)$ had light chain disease (2 cases with kappa involvement and 2 cases with lambda involvement). Therefore, light chain cast nephropathy may have accounted for the renal impairment in the majority of our cases.It is also documented that hypercalcaemia associated with osteolysis by myeloma cells and hyperviscosity syndromes causes renal dysfunction. Unlike other reports, ${ }^{(6)}$ hypocalcaemia was more common than hypercalcaemia in our study; hypercalcaemia was seen in only one case, but this singular case had renal impairment. Renal dysfunction may be irreversible if not managed on time and this is associated with worse prognosis, thereforeprompt diagnosis and treatment is required as this improves outcome.

Erythropoietin is essential for red cell production and $>90 \%$ of this hormone is synthesized by the kidneys. Therefore it is not surprising that patients with renal impairment have anaemia. Our study showed only a weak negative correlation between serum creatinine levels and haemoglobin concentration; with a weak positivecorrelation between the eGFR and haemoglobin concentration. This may be due to the fact that anaemia in $\mathrm{MM}$ is multifactorialThe proliferation of the malignant plasma cells in the marrow causes anaemia and the plasma cells also secrete interleukin 6 which stimulates hepcidin, causing anaemia of chronic inflammation due 
to inhibition of absorption of iron in the gut and inhibition of uptake of macrophage iron by developing erythroblasts in the marrow.

\section{Conclusion}

Our study revealed a lower median age for onset of myeloma which may be due to racial predisposition of blacks in developing MM. We also found that $20 \%$ uncharacteristically had hypocalcaemia at diagnosis, while only $6.7 \%$ had hypercalcaemia. More than half had renal impairment which may have been attributed to free light chains or hypercalcaemia.

\section{Recommendation}

This study was done using a small number of MM cases, therefore larger multi-centre studies in our environment are encouraged.

\section{Limitations Of The Study}

Due to lack of facility to assess both beta-2-microglobulin and lactate dehydrogenase in our centre, these investigations were not done for any patient, therefore staging of the MM using the revised International Staging System was not done.

\section{References}

[1]. A Palumbo, K Anderson,Multiple Myeloma. N Engl J Med 2011; 364:1046-1060

[2]. SV Rajkumar, S Kumar,Multiple Myeloma: Diagnosis and Treatment.Mayo Clin Proc. 2016 Jan;91(1):101-19. doi: 10.1016/j.mayocp.2015.11.007.

[3]. J Caers,I Vande Broek, H De Reare, I Michaux, F Trullemans, R Schots, et al. Multiple Myeloma - An update on diagnosis and treatment. Eur J. Haematol Nov. $2008: 329-43$

[4]. KC Nau, WD Lewis, Multiple Myeloma; Diagnosis and Treatment. Am Fam Physician $2008: 78$ (7) : 853 - 9

[5]. AJ Waxman, PJ Mink, SS Devesa, et al. Racial disparities in incidence and outcome in multiple myeloma: a population-based study. Blood. 2010;116(25):5501-5506. doi:10.1182/blood-2010-07-298760.

[6]. AVHoffbrand, PAHMoss. Multiple Myeloma and related disorders. Chapter 21 inHoffbrand AV, Moss PAH,Hoffbrand's Essential Haematology. Seventh edition. John Wiley \& Sons Ltd. 2016: pp 228 - 241

[7]. DT Koura, AA Langston, Inherited predisposition to multiple myeloma.TherAdvHematol. 2013 Aug;4(4):291-7. doi: $10.1177 / 2040620713485375$.

[8]. AAgarwal, IGhobrial, Monoclonal gammopathy of undetermined significance and Smoldering Multiple Myeloma: A review of the current understanding of epidemiology, biology, risk stratification and management of myeloma precursor disease. Clinical cancer research : an official journal of the American Association for Cancer Research. 2013;19(5):985-994. doi:10.1158/1078-0432.CCR$12-2922$.

[9]. JLHarousseau, MDreyling, Multiple Myeloma; ESMO Clinical Recommendation for Diagnosis, Treatment and follow up. Ann Oncol 2009; 20 Supp $4: 97-9$

[10]. D Maillet, L Montiel-Cervantes , Y Padilla-González, E Sánchez-Cortés , M Xolotl-Castillo , J Vela-Ojed, E Reyes-Maldonado . Serum calcium is an independent prognostic factor of overall survival in Mexican patients with multiple myeloma. Rev Invest Clin. 2012 Jan-Feb;64(1):17-24.

[11]. S-MBang, RKyle, SRajkumar, SKumar. Treatment patterns and outcomes in elderly patients with multiple myeloma. Leukemia. 2013;27(4):971-974. doi:10.1038/leu.2012.259.

[12]. APNoriega Aldave, SJaiswal. Severe resistant hypocalcemia in multiple myeloma after zoledronic acid administration: a case report. Journal of Medical Case Reports. 2014;8:353. doi:10.1186/1752-1947-8-353.

[13]. AMansinho, ARFerreira, LCosta. Hypocalcemia in patients with metastatic bone disease treated with denosumab.Ann Joint $2016 ; 1: 16$

[14]. NRDash, BMohanty. "Biochemical Profile and Electrophoretic Pattern in Multiple Myeloma Patients". Journal of Evidence Based Medicine and Healtthcare; Volume2, Issue 39, Sept. 2015; Page 6166 - 6170

[15]. GSChopra, PKGupta, DKMishra. The Evaluation of Suspected Monoclonal Gammapathies: The Experience in a Tertiary Care Hospital. MJAFI 2006; 62:134 - 37

[16]. STripathy. The Role of Serum Protein Electrophoresis in the Detection of Multiple Myeloma. Journal of Clinical and Diagnostic Research - 2012 November, Vol - 6 (9)

[17]. SVRajkumar. Multiple myeloma: 2016 update on diagnosis, risk-stratification, and management. Am J Hematol. 2016 Jul; 91 (7): 719-34

[18]. CAHutchison, VBatuman, JBehrens, et al. The Pathogenesis and Diagnosis of Acute Kidney Injury in Multiple Myeloma. Nat Rev Nephrol 2011; 8: $43-57$

[19]. CAHutchison, PCockwell, SStringer, et al. Early Education of Serum Free Light Chain Associated with Renal Recovery in Myeloma kidney. JAM SocNephrol 2011; 22: 1129 - 39

[20]. HLudwig, GPohl, AOsterborg. Anemia in multiple myeloma. ClinAdvHematolOncol. 2004 Apr;2(4):233-41. 